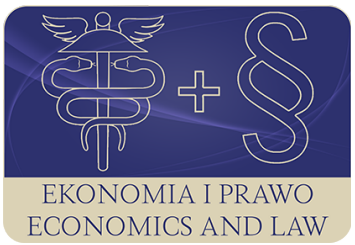

EKONOMIA I PRAWO. ECONOMICS AND LAW

Volume 19, Issue 1, March 2020

p-ISSN 1898-2255, e-ISSN 2392-1625

www.economicsandlaw.pl

ORIGINAL ARTICLE

received 13.07.2019; revised 18.12.2019; accepted 31.03.2020

Citation: Miłaszewicz, D. (2020). Behavioural insights as the example of innovative approach to public policymaking. Ekonomia i Prawo. Economics and Law, 19(1): 73-84. doi:10.12775/EiP.2020.006.

\title{
Behavioural insights as the example of innovative approach to public policymaking
}

\author{
DANUTA MIEASZEWICZ \\ University of Szczecin, Faculty of Economics, Finance and Management, Department of Economics, \\ ul. Mickiewicza 64, 71-101 Szczecin, Poland \\ $\square$ danuta.milaszewicz@usz.edu.pl \\ (D) orcid.org/0000-0001-6429-7331
}

\begin{abstract}
Motivation: Among the theorists and practitioners of public policy is growing awareness of the need to change the assumptions of designing and implementing public policy. The findings of social sciences, especially behavioural economics and experiments used within it, provide knowledge on how within public policy to influence the way people think and make decisions. Using behavioural insights in public policy is innovative opportunity to significantly increase the effectiveness of many public activities.

Aim: The purpose of this article is to analyse behavioural insights as an innovative approach to public policy making and the current strategies for the policy and design of public regulations based on them.

Results: Based on the literature on the subject and the analysis of the experience of nudge units, the principles of introducing behavioural insights as an innovative approach in public policy were indicated. They are currently being refined and recommended as ready-toapply strategies for behavioural changes.
\end{abstract}

Keywords: behavioural insight; public innovation; public policy

JEL: D91; E71; O38

\section{Introduction}

Since many years in the literature on the subject and practice in public management, the importance of supporting public policy with evidence, also derived 
from scientific research, has been emphasized. Evidence-based public policy, regardless of the schools of thought and typology distinguished in the literature ${ }^{1}$, is a discourse or set of methods that informs the political process and is not intended to directly influence policy objectives. Advocates a more rational, rigorous and systematic approach to public policy making. It is based on the premise that political decisions should be better informed by available evidence (including scientific evidence), which are seen as useful and necessary data for decision-makers in their current consideration of policy development. These decisions should include a rational analysis of the available evidence, and public policy based on systematic evidence gives better results (Head, 2010; Parkhurst, 2017, pp. 14-15).

In recent years, social sciences, especially behavioural economy, questioning the full instrumental rationality of individuals and providing many intellectual insights and patterns on the behaviour of individuals inconsistent with the homo oeconomicus model, has become the support for the scientific approach to create evidence-based public policy. Thanks to its theories and results of research, providing knowledge on how people actually make decisions and act in everyday life, it is possible to create more effective and efficient public policy. Based on this knowledge, behavioural insights are currently being introduced into public policy, and specific sets of rules are applied to its creation and implementation, in many countries.

The main objective of the study is to analyse behavioural insights as an innovative approach to public policy making and the current strategies for the policy and design of public regulations based on them.

\section{Literature review: behaviour insights in public policy}

In carried out studies referring to various aspects of human behaviour social sciences proves that human choices vary depending on the circumstances, place, time, norms and social influences, emotional judgments, cognitive distortions and biases, simplifying reasoning principles applied and at the same time on how and in what circumstances the choice is made (the choice architecture). Behavioural insights, resulting from numerous experiments, indicate that people, using two systems of thinking (Foley \& Griffiths, 2011, p. 21; Gordon, 2011, p. 3; Miller et al., 2015, p. 240; Thaler, 2015, p. 9):

- make choices rather relatively than absolutely, act intuitively in many situations, are prone to pre-conceptions and biases;

- struggle to cope with information overload, therefore they use current and easily available information;

- put undue attention to certain factors, and ignore important decision-making factors;

- have limited cognitive resources;

${ }^{1}$ For different schools of thought and typologies, see French (2019, pp. 151-168), Head (2016, pp. 473-474) and Newman (2017, pp. 211-226). 
- make decisions emotionally, instinctively, implement them slowly or do not implement them at all;

- are also excessively self-confident, act mechanically, under the influence of impulses, rapidly changing emotional states;

- make mistakes in assessing the probability of future events;

- are guided by the decisions of other people, relations with them and social norms.

The use of these insights in public policy means that its creators, in the context of people's reactions to public interventions, cease to be subject to the illusion of rationality created by traditional neoclassical economics. Therefore, understanding the reasons underlying human behavior, human choices and limited rationality that guide the reactions of public policy recipients is a key element of effective policy making. This explains why the recipients of a given policy react to public intervention in a specific way, often significantly different from the expectations of the intervention's authors (see Ciriolo 2011; Simon, 1997).

Behavioural insights, as lessons from behavioural economics, focusing on how people actually make choices and contribute to delivering more targeted and effective policy solutions. The understanding of human behaviour is informing policy-making, contributing to the design of new forms of intervention, as well as complementing traditional approaches (i.e. regulations, incentives, and information requirements). The last few years have seen major developments in the application of behavioural insights to different policy areas such as competition, consumer protection, education, energy, environment, finance, health and safety, labour market, public service delivery, taxes and telecommunications (see Lourenco et. al., 2016; OECD, 2017a). Policy initiatives based on findings of behavioral economics can be divided into (Lourenco et. al., 2016, p. 6; OECD, 2017b, p. 77):

- behaviourally-tested (i.e. initiatives based on an ad-hoc test, or scaled out after an initial experiment);

- behaviourally-informed (i.e. initiatives designed explicitly on previously existing behavioural evidence);

- behaviourally-aligned (initiatives that, at least a posteriori, can be found to be in line with behavioural evidence).

Change in individual, collective as well as corporate thinking and behavior aimed at increasing welfare should be the main goal of public policy. Therefore, behavioural economics and behavioural insights provide knowledge on how smoothly influence people's way of thinking and decision making, to understand their motivations, incentives and behaviors and guiding them towards a desired result. The scope of behavioural insights applications to create and implement policy is therefore broad, ranging from providing information to citizens, businesses and other administrations (in the context of public service), by influencing the way laws and regulations are developed and implemented, up to their implications for how grants, subsidies, taxes and charges are targeted, and for how institutions can become more effective in achieving their goals (Eu- 
ropean Commission, 2017, p. 34). Although behavioural insights can be used at various stages in the policy-making process (when designing and assessing its implementation or at the end of the policy cycle to assess the effectiveness of its implementation), they are often used relatively late in the design of policy, when a policy is already in place, for example to fine-tune and improve implementation and compliance (OECD, 2017a, p. 13).

In order to develop and enhance behavioural insights application to create public policy governments should (OECD, 2017b, p. 44):

- extend the application of behavioural insights and focus not only on individual behaviour but also the processes governing the work of public organisations, as well as the behaviour of regulated firms (e.g. capital markets/banks; energy consumption for large industrial firms; means of transportation used by big business, etc.);

- look alternatively at behaviourally informed policy solutions that are customized to the needs of only a part of the population;

- apply behavioural insights over the policy cycle. Behavioural insights are often used in late stage of the design of policy. There is a great potential to also apply behavioural insights to evaluate the effectiveness of policies and in the early design phase of policies to better understand the problem to be addressed;

- establish capacity, consistent methodologies and quality control processes for the application of behavioural insights. This includes the development of processes to determine in which case a policy problem can be addressed through behavioural insights (or not), internal capacity building within the public administration through information and training programmes, investment in the collection of robust data and information to ground behavioural interventions in solid evidence, and encouraging efforts to validate experimental results through replication and the application of identified solutions in diverse contexts;

- monitor the impact of behavioural insights approaches to identify shortterm and long-term effects;

- enhance the transparency and accountability of the use of behavioural insights by publishing both successful and unsuccessful applications and disclosing information about the actual costs and benefits of applying behavioural insights. This helps to address ethical concerns about the use of behavioural insights and enhances the credibility and public acceptance of the tool.

\section{Methods}

The intended goal of the article has been achieved and the formulation of conclusions was conducted thanks to the critical review of literature, primarily articles published in current journals dedicated to research in the field of behavioural insights and public policy, and the desk research method. This enabled 
the author to look at the analysed problem from the theoretical point of view as well as the practice of public policy.

Literature study involved a database search to identify any publications described by keywords containing the following two phrases: behavioural insights and public policy. It enabled the author to narrow down the search results within the rich body of literature on behavioural economics to the most recent ones, which explore how the findings related to behavioural economics may be applied to public policy based on evidence. Desk research, on the other hand, involved an overview of studies, reports and other materials published by international organisations (such as the OECD or the EU) and the so-called behavioural or nudging units, which have been created in several countries in order to apply behavioural insight to solving specific problems. These studies offer various principles and strategies for formulating and introducing behavioural changes by the public policy. An analysis of those materials enabled the author to develop and present classification of the principles of applying behavioural insights in public policy into two groups: methods of impact on individuals and methods of developing and applying projects of behavioural policy.

\section{Results: strategies and rules for applying behavioural insights in public policy}

The broader use of behavioural insights for the design and implementation of public policy was initiated by the concepts of libertarian paternalism introducing the concept of choice architecture. Libertarian paternalism is a form of paternalism, libertarian in spirit, that should be acceptable to those who are firmly committed to freedom of choice (on grounds of either autonomy or welfare) and attempts to influence the choices of affected parties in a way that will make choosers better off (Sunstein \& Thaler, 2003, p. 1162; Thaler \& Sunstein, 2003, pp. 175-179). Within its scope, taking an assumption that individuals do not make decisions in the vacuum and for real people details forming the conditions of the choice made can be important (Thaler et al., 2012, p. 428) indicates that the decision-making environment can be appropriately created and changed, influencing the conditions of the decisions made. The formulation of the interpretive framework, differently called as choice architecture, for individual decisions has a huge impact on the result (Thaler \& Sunstein, 2008, pp. 82, 239).

Application of behavioural insights as innovative solutions in evidence-based public policy has been growing in popularity among scientists, policy makers and international organizations (World Bank, United Nations, OECD, European Commission) promoting they in last years. But, to transpose behavioural insights from the academic studies of behaviour into policy-making, the different concept and findings need to be taken into the political and administrative process. 
Enthusiastic adoption of behavioural insights by the government and practitioners of public policy led to launching of various policy initiatives, creation of so called central, local or government nudging units, as well as less formalized teams, appointed ad hoc to apply behavioural insights to solve specific problems. The application of behavioural economics to public policy through dedicated behavioural units or nudge units (or the ad hoc governmental teams) involved in applying behavioural insights to policy issues is transforming the way governments design policies as well as operate and deliver services. These units are models for social entrepreneurship and partnerships in policymaking with academia and social purpose entities. They conduct policy experimentation and use evidence-based tools, such as randomised control trials (Makki, 2017). Based on their experience, these teams develop and make available the principles and strategies for formulating and implementing behavioral changes through public policy. These principles can, and what is more, should be used by other authors of behavioral policy and to solve other problems. In this way, responsible organizations and actors employed in the formulation and implementation of such policies can acquire the necessary competences and capabilities to better perform their functions (Kuehnhanss, 2019, pp. 14-49).

Proposed through these teams principles of creating public policy based on behavioural insights are known as strategies for policy and regulatory design (Olejniczak \& Śliwowski, 2015, p. 77), behavioural change principles, basic principles of effective choice architecture or good choice architecture (Thaler et al., 2012, pp. 432, 436). These rules are a set of guidelines for the architects of choice involved in the design of public interventions and usually have the form of catchy mnemonic instructions, indicating the main methods of influencing the decisions of individuals.

The rules proposed as acronyms NUDGES and MINDSPACE (described in table 1) are the best known and often applied. The nudges, derived from the approach of libertarian paternalism, is a very distinct form of applying behavioural insights to policy. The nudge is 'any aspect of the choice architecture that alters people's behaviour in a predictable way without forbidding any options or significantly changing their economic incentives. To count as a mere nudge, the intervention must be easy and cheap to avoid' (Thaler \& Sunstein, 2008, p. 6). NUDGEs are small, cost-effective and choice architecture-type interventions that seek to alter people's behaviour but without drastically restricting their choices. They use of automatic defaults (Makki, 2017). Strategy NUDGE is a set of simple recommendations, what and how to do to be successful and focuses on counteracting cognitive errors, which are the source of an intuitive, fast thinking system (so-called System 1). This simple set of rules is used for choice architects when they create behaviour change policy (Thaler et al., 2012, p. 437).

Strategy MINDSPACE popularise the most robust behavioural insights among policy-makers and refers both to System 1 of thinking, and to so-called System 2 - a system of reflective thinking. Some of the elements of MIND- 
SPACE have been developed to explain largely automatic effects on behaviour (e.g. N, D, S, P, A) while other effects relate to elements that draw more on reflective processing (e.g. M, I, C, E) (Dolan et al., 2010, p. 18). It is a descriptive strategy - it showing the mechanisms and principles of operation of the choice architects, it also creates choices in relation to the design of public activities (Olejniczak \& Śliwowski, 2015, p. 78). This strategy can help in situations if government is attempting to shape behaviour and it should do so as effectively as possible. The policy makers can use MINDSPACE to improve the effectiveness of existing and new behaviour change policies (Dolan, 2013, p. 197; Dolan et al., 2010, pp. 18-28; 2012, pp. 264-277).

Other strategies for behavioural changes focus on creating the right institutional framework that enables conscious, critical and active participation of citizens in decision making (John et al., 2011, pp. 18-20). One of these is STEER - one of the possibilities, the so-called debiasing. This strategy stimulates in citizens the awareness of their limitations in making decisions and teaches them how to make important decisions in a more conscious way. In short - it teaches reflexivity in making decisions (Jones et al., 2013, pp. 177-182).

Next strategy - THINK — can be seen as an alternative to nudge (John et al., 2011, p. 19). The key ways of achieving behavioural change in this approach are debate self-ownership and collective decision-making. This strategy can be expensive to implement, therefore the seem to be better when concerns addressing thorny public problems than day-to-day issues of behavioural change (John, 2018, p. 18).

In practice, methods for developing behavioral policy projects have also been developed. One of them, proposed by the UK nudge unit (United Kingdom's Behavioural Insights Team), descript a fuller method for developing projects of behavioural policy and has four main stages (Service et. al., 2014, p. 7):

- define the outcome - identify exactly what behaviour is to be influenced. Consider how this can be measured reliably and efficiently. Establish how large a change would make the project worthwhile, and over what time period;

- understand the context — visit the situations and people involved in the behaviour, and understand the context from their perspective. Use this opportunity to develop new insights and design a sensitive and feasible intervention; - build your intervention - use the EAST framework (described in table 1) to generate your behavioural insights;

- test, learn, adapt, share (see table 1) - put your intervention into practice so its effects can be reliably measured. Wherever possible, use randomised controlled trials to evaluate its interventions. These introduce a control group so you can understand what would have happened if you had done nothing.

The framework EAST is explicitly designed for applying behavioural insights in practice, and should be used alongside the existing strategies for policy and regulatory design such as MINDSPACE or Test, Learn, Adapt (Halpern, 2015, p. 149). The EAST principles apply equally to policymakers themselves. 
But, this framework cannot be applied in isolation from a good understanding of the nature and context of the problem.

Methodology 'test, learn, adapt, share' organized around four key principles (see table 1), was proposed for the selection of effective policy options that successfully correspond with its objectives and have the greatest impact. This methodology sets out a series of steps to carry out randomized controlled trials (RCTs) to test the effectiveness of policy interventions and to continuously improve the design and implementation of public policies (see Haynes, et. al., 2012). Whereas sharing can lead to more robust behavioural policy initiatives built with a greater understanding of 'what works' and of the boundary conditions or cultural barriers that might apply (Lourenco et. al., 2016, p. 13).

The experiences in the conduct of behavioural public policies indicates that government or other public bodies are advised to pay heed to the following necessary components that can be summarized in the simple mnemonic of APPLES (see table 1). This mnemonic summarize of the key success factors for developing an effective behavioural insights function, as a prompt to help others government to find the best way mainstream behaviour change as a core public policy mechanism for ensuring the public goods (Pykett et. al., 2017, pp. 69-84).

\section{Conclusion}

Public policy, to promote change in behaviour can do so in a traditional way, or use a more scientific and innovative approach based on the use of behavioural insights, in particular the findings of behavioural economics resulting from experimental research. This second method allows for a better understanding of human reactions and behaviours, which are a response to the regulations being introduced. Behavioural insights increasingly contributes to shaping and implementing public policy and are gaining popularity among governments as a useful tool to create new solutions that can be relatively simple and particularly effective. They are being applied by governments at different stages of the policy process, with the aim of making it work better. Behavioural insights are about taking an evidence-based approach to policy making, empirically testing different approaches to solving issues and problems before considering their implementation. They offer a powerful tool to reshape and design new evidence-based policy (OECD, 2017b, p. 168).

Due to the growing number of examples of their use in public policy, proving their significant positive effects, they can not be seen as trendy, temporary deviations from the tradition of designing and implementing this policy. They have rooted in many ways, in many countries around the world and in many sectors and areas of public policy. This is evidenced not only by the amount of institutionalized and non-institutionalized formation introducing behavioural insights to new public policy projects, but also by more and more examples of the formation of non-governmental teams using the developed behavioural strategies for policy and regulatory design and implementation, described in this article. 
Although behavioural insights are currently used mainly in the areas in which they were first introduced, to make the most of their potential, rules and standards (strategies) should be established to guide their future applications, and retain citizens' confidence in public authorities. If behavioural insights are to be used more widely as a solid policy tool, the results of their testing as part of experiments and current applications should be published and made available, as they are fundamental to behavioural practitioners in public policy.

Behavioural insights offer a powerful tool to reshape and design new evidence-based policy. However, potential further applications of behavioural insights in developing and maintaining a policy depend on their interpretation and assumptions used in translating empirical evidence about people making decisions for political interventions. To appreciate the opportunities that behavioural observations may offer, it is necessary to consider the development of appropriate research and policy programs and to highlight both their normative and positive bases (Kuehnhanss, 2019, pp. 14-40).

\section{References}

Ciriolo, E. (2011). Behavioural economics in the European Commission: past, present and future. Retrieved 02.04.2019 from https://www.oxera.com.

Dolan, P. (2013). Influencing the financial behaviour of individuals: the mindspace way. In A. Oliver (Ed.), Behavioural public policy. Cambridge: Cambridge University Press.

Dolan, P., Hallsworth, M., Halpern, D., King, D., \& Vlaev, I. (2010). Mindspace: influencing behaviour through public policy. Retrieved 02.04.2019 from https://www.instituteforgovernment.org.uk.

Dolan, P., Hallsworth, M., Halpern, D., King, D., Metcalfe, R., \& Vlaev, I. (2012). Influencing behavior: the mindspace way. Journal of Economic Psychology, 33(1). doi:10.1016/j.joep.2011.10.009.

European Commission. (2017). Quality of public administration: a toolbox for practitioners. doi:10.2767/483489.

Foley, B. \& Griffiths, S. (2011). Engaging behaviour: behavioural economics and citizen engagement. Retrieved 02.04.2019 from https://research.gold.ac.uk.

French, R.D. (2019). Is it time to give up on evidence-based policy? Four answers. Policy \& Politics, 47(1). doi:10.1332/030557318X15333033508220.

Gordon, W. (2011). Behavioural economics and qualitative research: a marriage made in heaven? International Journal of Market Research, 53(2). doi:10.2501/ ijmr-53-2-171-186.

Halpern, D. (2015). Inside the nudge unit. how small changes can make a big difference. London: WH Allen.

Haynes, L., Service, O., Goldacre, B., \& Torgerson, D. (2012). Test, learn, adapt: developing public policy with randomised controlled trials. Retrieved 12.05.2019 from https://gov.uk. 
Head, B.W. (2010). Reconsidering evidence-based policy: key issues and challenges. Policy and Society, 29(2). doi:10.1016/j.polsoc.2010.03.001.

Head, B.W. (2016). Toward more 'evidence-informed' policy making? Public Administration Review, 76(3). doi:10.1111/puar.12475.

John, P. (2018). How far to nugde? Assessing behavioral public policy. Northampton: Edward Elgar. doi:10.4337/9781786430557.

John, P., Cotterill, S., Richardson, L., Moseley, A., Smith, G., Stoker, G., \& Wales, C. (2011). Nudge, nudge, think, think: using experiments to change civic behavior. London-New York: Bloomsbury Academic.

Jones, R., Pykett, J., \& Whitehead, M. (2013). Changing behaviours: on the rise of the psychological state. Cheltenham: Edward Elgar.

Kuehnhanss, C.R. (2019). The challenges of behavioural insights for effective policy design. Policy and Society, 38(1). doi:10.1080/14494035.2018.1511188.

Lourenco, J.S., Ciriolo, E., Almeida, S.R., \& Troussard ,X. (2016). Behavioural insights applied to policy: European report 2016. doi:10.2760/903938.

Makki, F. (2017). Nudge units are just the tool for effective policy. Retrieved 15.05.2019 from http://www.thenational.ae.

Miller, J.E., Amit, E., \& Posten, A.-Ch. (2015). Behavioral Economics. In H. Ten Have (Ed.), Encyclopedia of global bioethics. Jersey: Foster Academic.

Newman, J. (2017). Deconstructing the debate over evidence-based policy. Critical Policy Studies, 11(2). doi:10.1080/19460171.2016.1224724.

OECD. (2017a). Behavioural insights and public policy: lessons from around the world. doi:10.1787/9789264270480-en.

OECD. (2017b). Government at a glance 2017. doi:10.1787/gov_glance-2017-en.

Olejniczak, K., \& Śliwowski, P. (2015). Towards behaviorally informed public interventions. Management and Business Administration: Central Europe, 23(2). doi:10.7206/mba.ce.2084-3356.142.

Parkhurst, J. (2017). The politics of evidence: from evidence-based policy to the good governance of evidence. Abingdon: Routledge.

Pykett, J., Howell, R., Lilley, R., Jones, R., \& Whitehead, M. (2017). Governing mindfully: shaping policy makers' emotional engagements with behaviour change. In E. Jupp, J. Pykett, \& F.M. Smith (Eds.), Emotional states: sites and spaces of affective governance. London-New York: Routledge.

Service, O., Hallsworth, M., Halpern, D., Algate F., Gallagher, R., Nguyen,... Kirkma, E. (2014). EAST: four simple ways to apply behavioural insights. Retrieved 18.05.2019 from http://www.behaviouralinsights.co.uk.

Simon, H.A. (1997). Administrative behaviour: a study of decision-making processes in administrative organizations. New York: Free Press.

Sunstein, C.R., \& Thaler, R.H. (2003). Libertarian paternalism is not an oxymoron. The University of Chicago Law Review, 70(4). doi:10.2139/ssrn.405940.

Thaler, R.H. (2015). Misbehaving: the making of behavioral economics. New York: W.W. Norton.

Thaler, R.H., \& Sunstein, C.R. (2003). Libertarian paternalism. American Economic Review, 93(2). doi:10.1257/000282803321947001. 
Thaler, R.H., Sunstein, C.R. (2008). Nudge: improving decisions about health, wealth and happiness. New Haven: Yale University Press.

Thaler, R.H., Sunstein, C.R., \& Balz, J. (2012). Choice architecture. In E. Shafir (Ed.), The behavioral foundations of public policy. Princeton: Princeton University Press.

\section{Acknowledgements}

Author contributions: author has given an approval to the final version of the article.

Funding: this research was funded by the University of Szczecin, Faculty of Economics, Finance and Management, Department of Economics statutory sources.

Note: the results of this study were presented at 8th International Scientific Conference: Contemporary Economic Problems 'Social-economic problems in the era of globalization: theory and practice' (May, 22, 2019, Torun, Poland). 


\section{Appendix}

Table 1.

\section{Principles of applying behavioural insights in public policy}

\begin{tabular}{|c|c|c|}
\hline Methodology & Name & Description \\
\hline & $\mathrm{N}$ & incentives - create an incentive system \\
\hline 昙 & $\mathrm{U}$ & understand choice mapping — understand how the selection process proceeds \\
\hline 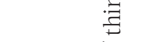 & $\mathrm{D}$ & defaults matter — remember that settings and default options are crucial \\
\hline$\stackrel{\stackrel{+}{\circ}}{\rightleftarrows}$ & G & $\begin{array}{l}\text { give feedback - provide feedback that will help people to understand, therefore inform, } \\
\text { warn against failure, praise for successes }\end{array}$ \\
\hline $\begin{array}{c}\sum^{\infty} \\
5 \\
5 \\
0\end{array}$ & E & $\begin{array}{l}\text { expect error - remember that people make errors - a good project of behavioural } \\
\text { change that takes into account and minimizes penalties for these errors }\end{array}$ \\
\hline 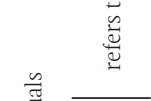 & S & $\begin{array}{l}\text { structure complex choices - try to simplify the possibilities, do not multiply the alter- } \\
\text { natives - the more choices people will have, the more complicated and problematic } \\
\text { they will become }\end{array}$ \\
\hline $\mathrm{N}$ & M & messenger — we are heavily influenced by who communicates information \\
\hline 㤩 & I & $\begin{array}{l}\text { incentives - our responses to incentives are shaped by predictable mental shortcuts } \\
\text { such as strongly avoiding losses }\end{array}$ \\
\hline 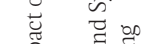 & $\mathrm{N}$ & norms — we are strongly influenced by what others do \\
\hline 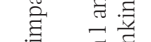 & $\mathrm{D}$ & defaults — we 'go with the flow' of pre-set options \\
\hline घี & $\mathrm{S}$ & salience - our attention is drawn to what is novel and seems relevant to us \\
\hline స & $\mathrm{P}$ & priming - our acts are often influenced by sub-conscious cues \\
\hline$\stackrel{0}{s}$ & A & affect — our emotional associations can powerfully shape our actions \\
\hline 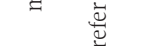 & $\mathrm{C}$ & commitments - we seek to be consistent with our public promises, and reciprocate acts \\
\hline & E & EGO — we act in ways that make us feel better about ourselves \\
\hline 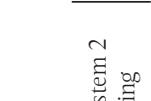 & STER & $\begin{array}{l}\text { based on workshops that are designed to make participants aware of how their brain } \\
\text { works and to make them aware of the acronyms used in everyday decisions; teaches } \\
\text { reflexivity in making decisions }\end{array}$ \\
\hline 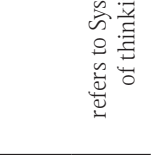 & THINK & $\begin{array}{l}\text { is giving citizens the space to think through and debate solutions and focuses on the pro- } \\
\text { cess of developing public opinion and deliberate citizenships. strategy is giving citizens } \\
\text { the space to think through and debate solutions and focuses on the process of developing } \\
\text { public opinion and deliberate citizenships; the basis for overcoming cognitive errors } \\
\text { and activating reflective thinking is deliberation }\end{array}$ \\
\hline \multirow{11}{*}{ 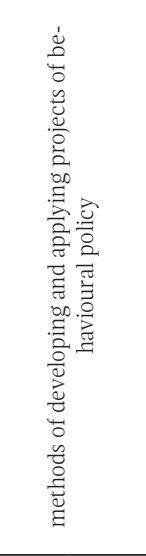 } & EAST & $\begin{array}{l}\text { to encourage any desired behaviour, the choices should be made simple and understand- } \\
\text { able (easy), salient in citizens' lives (attractive), socially encouraged (social), and present } \\
\text { at the key time in the decision-making process (timely) }\end{array}$ \\
\hline & TEST & $\begin{array}{l}\text { identify the policy interventions to be compared and put in places measures for evaluat- } \\
\text { ing their effectiveness }\end{array}$ \\
\hline & LEARN & measure the results and identify 'what works' \\
\hline & ADOPT & use findings to adjust the policy intervention accordingly \\
\hline & SHARE & propagate the results and insights \\
\hline & A & $\begin{array}{l}\text { for administration and the importance of gaining traction within the public administra- } \\
\text { tion }\end{array}$ \\
\hline & $\mathrm{P}$ & for politics, because it is critical to get political buy-in \\
\hline & $\mathrm{P}$ & for people who need to do the job and need to have the necessary skills and knowledge \\
\hline & $\mathrm{L}$ & for the location of the unit or units who will work on behavioural insights \\
\hline & E & $\begin{array}{l}\text { for experimentation, as it helps to start with a few quick wins to show some results } \\
\text { and develop a number of longer-term projects }\end{array}$ \\
\hline & S & for scholarship and academia which can be an essential resource \\
\hline
\end{tabular}

Source: Own preparation based on Dolan (2013, p. 197), Dolan et al. (2010, pp. 18-28; 2012), Halpern (2015, p. 60), John (2018, p. 18), Jones et al. (2013, pp. 177-182), Service et. al. (2014, p. 7), Thaler at al. (2012, p. 437). 